\title{
Microstructure and Dry Friction of 2205 Dual-Phase Steel during Solution Precipitation
}

\author{
Weijie Yang $\left(\mathbb{D},{ }^{1}\right.$ Wenjun Meng $\mathbb{D}^{1},{ }^{1}$ and Xiaobing Dai $\mathbb{D}^{2}$ \\ ${ }^{1}$ School of Mechanical Engineering, Taiyuan University of Science and Technology, Taiyuan 030024, China \\ ${ }^{2}$ Chair of Materials Handling, Material Flow, Logistics, Technical University of Munich, Boltzmannstraße 15, \\ 85748 Garching, Germany \\ Correspondence should be addressed to Wenjun Meng; tyustmwj2021@163.com
}

Received 27 April 2021; Revised 14 May 2021; Accepted 20 May 2021; Published 29 May 2021

Academic Editor: Zhigang Tao

Copyright (C) 2021 Weijie Yang et al. This is an open access article distributed under the Creative Commons Attribution License, which permits unrestricted use, distribution, and reproduction in any medium, provided the original work is properly cited.

The friction and wear tests of 2205 dual-phase steel with different solution temperatures were carried out, and the effects of solution temperature on the microstructure and friction and wear properties of the steel were determined. Results show that, as the solution temperature increases, the morphology of the austenite phase in 2205 duplex stainless steel gradually changes from fibrous strips to short rods and islands with a more uniform distribution. Additionally, the ferrite content increases with a rise in solution temperature, reaching $56.3 \%$ after solution treatment at $1160^{\circ} \mathrm{C}$. It was also found that, between $1000^{\circ} \mathrm{C}$ and $1160^{\circ} \mathrm{C}$, the friction coefficient curves of 2205 dual-phase steel and silicon nitride balls have similar characteristics. Under $100 \mathrm{~N}$ dry friction, with the increase of solution temperature and oxygen distribution area, the wear mechanism of 2205 dual-phase steel gradually expanded from local oxidation wear to adhesive wear and exfoliation wear.

\section{Introduction}

Composed of austenite and ferrite, 2205 duplex stainless steel possesses great strength and corrosion resistance. It is widely used in the petrochemical, papermaking, and petroleum industries [1-7]. Because of the presence of both austenite and ferrite, 2205 duplex stainless steel possesses the properties of both of these phases. The existence of austenite can greatly reduce the brittleness of the ferrite and also improve the weldability of the material. Ferrite improves the resistance of the material to stress corrosion, and because of the simultaneous existence of these two phases, it can also inhibit grain growth [8-13]. However, the presence of these two phases also brings some disadvantages. A higher ferrite content in stainless steel increases the brittleness of the material. Moreover, due to the difference in deformation abilities between ferrite and austenite, the properties of the material in extremely hot or cold working conditions are inferior to those of single-phase stainless steel $[14,15]$.

Previous studies [16-22] have found that solution treatment is one of the main factors determining the two- phase ratio of duplex stainless steel. Different solid solution treatment processes not only cause 2205 duplex stainless steel to have different two-phase ratios but also lead to the precipitation of a secondary phase. This secondary phase often causes pitting corrosion of the steel and increases the tendency of stress corrosion cracking and corrosion fatigue cracking during usage. This in turn affects the corrosion resistance and mechanical properties of 2205 duplex stainless steel.

The mechanism of friction and wear is to explain the wear process of materials. It represents the formation of wear debris in the process of wear [23-25]. The wear mechanism can be understood by observing the worn surface. The most likely wear of duplex stainless steel in the wear process is adhesive wear, abrasive wear, and local oxidation wear. Sometimes, the duplex stainless steel will be exfoliated, worn, and abraded. The wear mechanism is also different. In the case of wear resistance of dual-phase steel, Wang et al. [26] reported the effects of dry friction and fretting amplitude in an aqueous solution on the fretting wear behavior of 2507 super-dual-phase stainless steel. The 
results showed that, under dry friction, the wear mechanism changed from local oxidation wear and local fatigue wear to oxidation wear, adhesion wear, and spalling wear. In an aqueous solution, the main wear mechanisms were mild oxidation wear and abrasive wear, accompanied by fatigue wear. Wang et al. [27] prepared a high nitrogen austenite layer on the surface of dual-phase steel and obtained a high nitrogen stainless steel layer with a uniform structure and easier subsequent processing.

In practical applications, dual-phase steel will suffer material loss from friction and wear. The friction and wear properties of duplex stainless steel are affected by the solution treatment. So far, there have been few studies on the wear resistance of 2205 dual-phase steel under different solution treatment conditions. Therefore, microstructure analysis and friction and wear tests for 2205 duplex stainless steel were carried out under different solid solution treatment conditions. The wear resistance of the material was evaluated to provide an important reference for the optimization of the production process and product quality control.

\section{Materials and Experiments}

Table 1 displays different chemical compositions of 2205 duplex stainless steel plates with $4 \mathrm{~mm}$ thickness. The solution test was carried out in a muffle furnace. Solution temperatures ranged from $1000^{\circ} \mathrm{C}$ to $1160^{\circ} \mathrm{C}$, at intervals of $40^{\circ} \mathrm{C}$, and the solution holding time was 40 minutes. After being removed from the solution, the sample was directly quenched with water.

The specimens used for the electron backscatter diffraction (EBSD) study were cut along the rolling direction, and the longitudinal sections (RD-ND) of the specimens were polished using standard metallographic procedures. Then, electrolysis was carried out in 20:1 ethanol and perchloric acid solution, with an electrolysis voltage of $20 \mathrm{~V}$ and current of $1 \mathrm{~A}$ to ensure the removal of any surface deformations. EBSD was carried out using a ZEISS Sigma 3000 field-emission scanning electron microscope.

The wear resistance of the 2205 dual-phase steel was characterized by exploring the friction and wear properties of the material after treatment at different temperatures. Before the experiment, the solid sample to be placed in the solution was cut into a $20 \mathrm{~mm} \times 10 \mathrm{~mm} \times 4 \mathrm{~mm}$ rectangular block. Next, the surface of the sample was polished to 3000 mesh and further polished with a diamond polishing agent. The reciprocating sliding friction test was carried out under dry conditions at room temperature using an MFT-5000 friction and wear tester from RTEC Instruments. The friction and wear tests were carried out with a $0.006 \mathrm{~mm}$ diameter silicon nitride ball. The trace length was $0.006 \mathrm{~mm}$ under $100 \mathrm{~N}$ applied load, the wear time was $30 \mathrm{~min}$, and the frequency was $1 \mathrm{~Hz}$. Table 2 shows the working parameters of the experiment. After the friction and wear test, the wear trace was observed with an online three-dimensional optical profilometer. The worn surface was observed using the X-ray diffraction (XRD). It was performed by using $\mathrm{Cu}-\mathrm{K} \alpha$ radiation. The scanning speed and the scan step size were $1^{\circ} \%$ min and $0.02^{\circ}$, respectively. The experimental data were processed by Jade 6.0 software.

\section{Results and Discussion}

3.1. Microstructure Analysis at Different Solution Temperatures. Figure 1 shows different morphologies of 2205 duplex stainless steel at different solution temperatures. The long-strip austenite phase is gray, and its width increases from $8-12 \mu \mathrm{m}$ at $1000^{\circ} \mathrm{C}$ to about $15 \mu \mathrm{m}$ at $1160^{\circ} \mathrm{C}$. The width of the austenite phase displays an obvious increase at temperatures above $1080^{\circ} \mathrm{C}$, as the phase map in Figure 1 illustrates. After heating and the solid solution treatment, a local phase boundary dissolution fracture occurred in the austenite phase. Its morphology changed from fiberboard strip morphology to long rod morphology. When the solution temperature increased to $1040^{\circ} \mathrm{C}$, the austenite phase with the long-rod shape transformed into a bamboo shape, and the grain/phase boundaries gradually became more regular. As the temperature increased to $1160^{\circ} \mathrm{C}$, the atomic diffusion speed increases, the grain boundaries and phase boundaries of austenite and ferrite become clearer after rolling and compression, and the long-rod austenite gradually forms a regular shape through recovery and recrystallization.

Figure 2 exhibits the X-ray diffraction patterns of the 2205 duplex stainless steel surface at different temperatures. Several oxides are formed on the surface of the sample after friction and wear such as $\mathrm{Mn}_{3} \mathrm{O}_{4}, \mathrm{Fe}_{2} \mathrm{O}_{3}$, and $\mathrm{Cr}_{2} \mathrm{O}_{3}$. It can be seen from Figure 2(a) that the relative intensity of the diffraction peak of the worn surface increases obviously with the increase of temperature, and the peak value of the curve deviates partially. The results show that friction and wear cause some microstructure changes in the dual-phase steel such as dislocations and lattice shifts. The ferrite content of 2205 duplex stainless steel was $53.5 \%$ after solution treatment at $1000^{\circ} \mathrm{C}$ (Figure 2(b)). With a rise in solution temperature, the ferrite content increased. After solid solution treatment at $1160^{\circ} \mathrm{C}$ and subsequent water cooling, the ferrite phase content in the microstructure reached $56.3 \%$. When the solution treatment temperature increased, a transformation in the two-phase composition occurred in the steel. It was a $\gamma \longrightarrow \alpha$ transformation, which means that ferrite in the steel increased gradually, while the level of austenite decreased [28].

\subsection{Effect of Solution Temperature on Friction Coefficient.} Figure 3 displays the real-time friction coefficient of 2205 dual-phase steel with different solution treatments under $100 \mathrm{~N}$ dry sliding friction. It can be seen from Figure 3 that the friction coefficient curves of 2205 dual-phase steel and silicon nitride balls have similar characteristics. The friction coefficient first increases rapidly, reaches a peak value, decreases quickly, and then increases gradually towards a stable value. The entire friction coefficient curve is divided into three stages. The first stage is the initial running-in stage [29]. In this stage, the material surface 
TABLE 1: Chemical composition of 2205 duplex stainless steel (wt\%).

\begin{tabular}{lccccccccc}
\hline $\mathrm{C}$ & $\mathrm{Cr}$ & $\mathrm{Mo}$ & $\mathrm{Ni}$ & $\mathrm{Si}$ & $\mathrm{S}$ & $\mathrm{Mn}$ & $\mathrm{P}$ & $\mathrm{N}$ & $\mathrm{Fe}$ \\
\hline 0.025 & 21.83 & 3.09 & 5.45 & 0.58 & 0.003 & 1.13 & 0.024 & 0.1699 & Balance \\
\hline
\end{tabular}

TABLE 2: Wear test parameters.

\begin{tabular}{lcccccc}
\hline Applied load $(\mathrm{N})$ & Balls & Balls' diameter $(\mathrm{m})$ & Trace length $(\mathrm{m})$ & Frequency $(\mathrm{Hz})$ & Temperature $\left({ }^{\circ} \mathrm{C}\right)$ & Total sliding distance $(\mathrm{m})$ \\
\hline 100 & $\mathrm{Si}_{3} \mathrm{~N}_{4}$ & 0.006 & 0.006 & 1 & $24 \pm 2$ & 0.36 \\
\hline
\end{tabular}

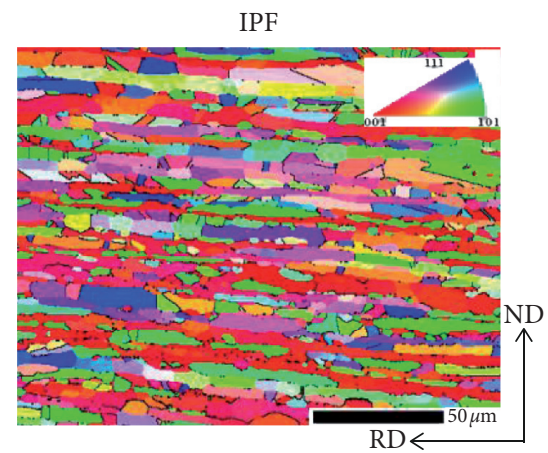

(a)

IPF

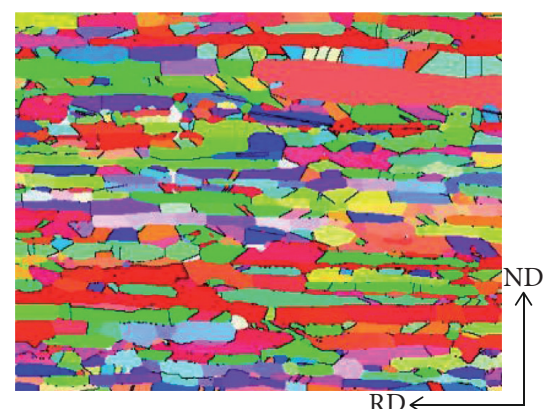

(d)

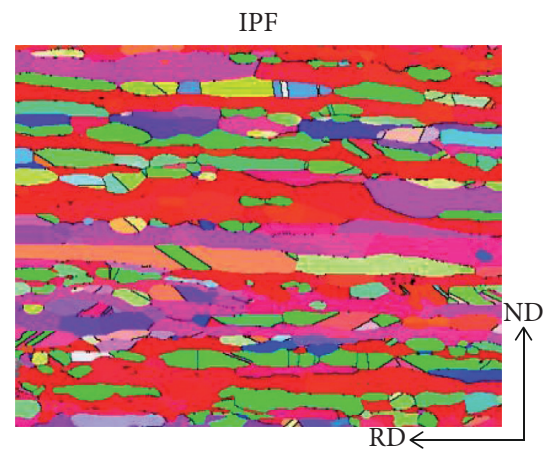

$\mathrm{RD}$

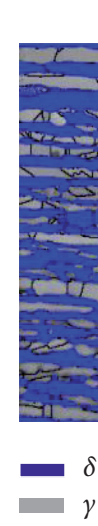

Phase map

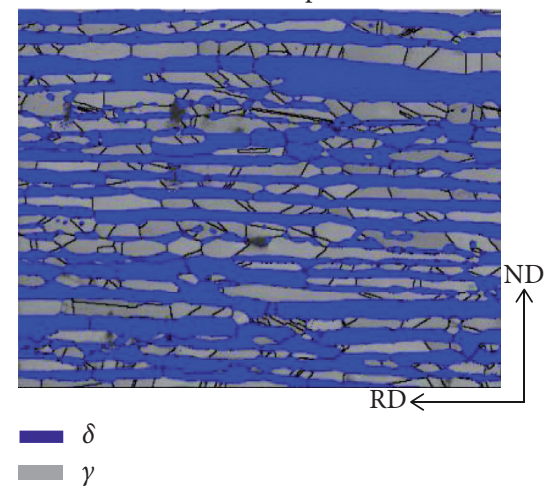

(e)

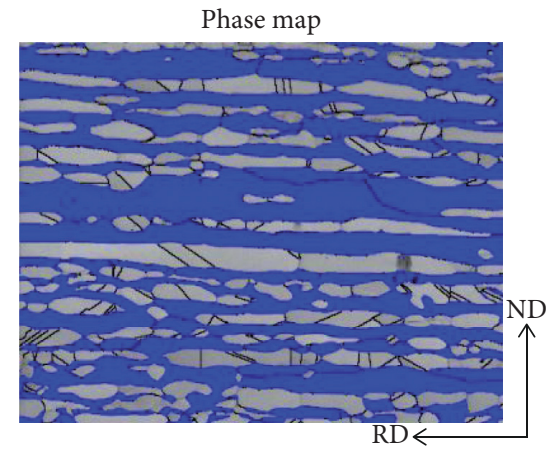

$\delta$

$\gamma$
Phase map

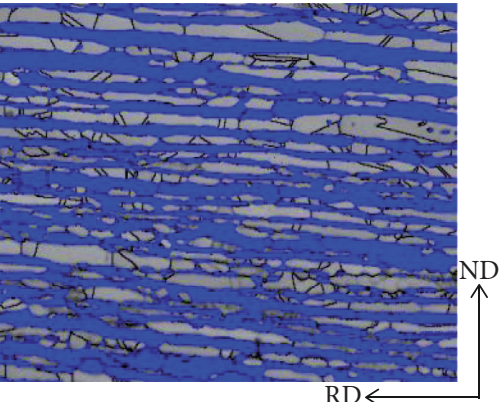

$\mathrm{RD}$

$$
\sqrt{20}
$$


IPF

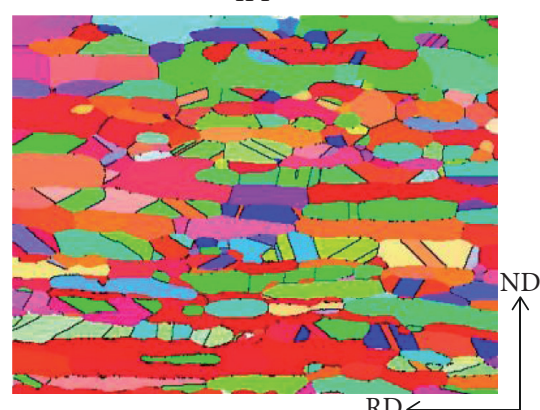

$\mathrm{RD}$

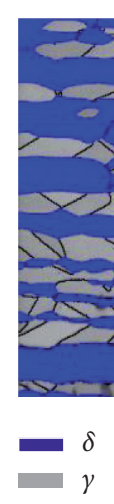

(j)

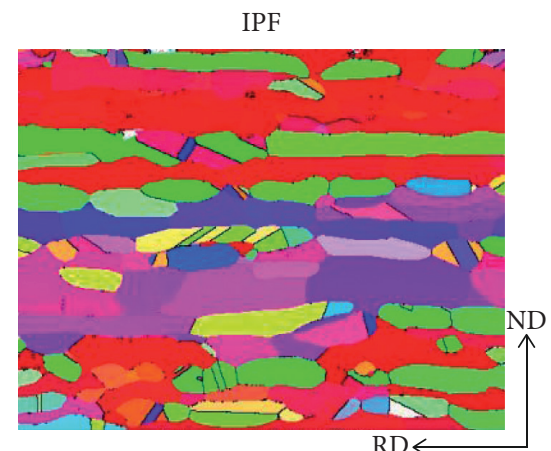

$\mathrm{RD} \leftarrow$
Phase map

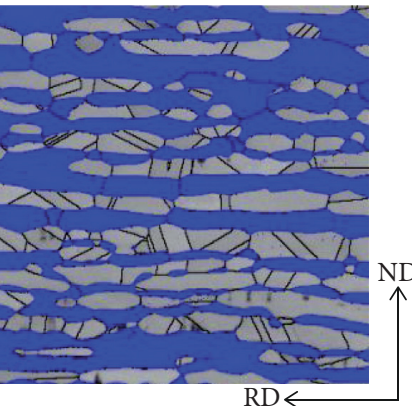

$\mathrm{RD}$

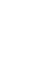

(k)

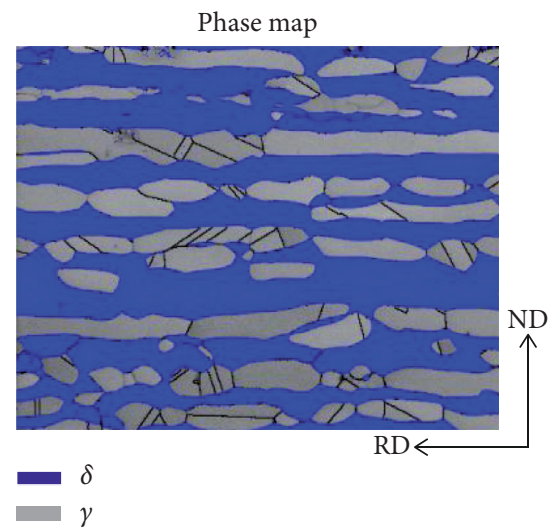

(n)

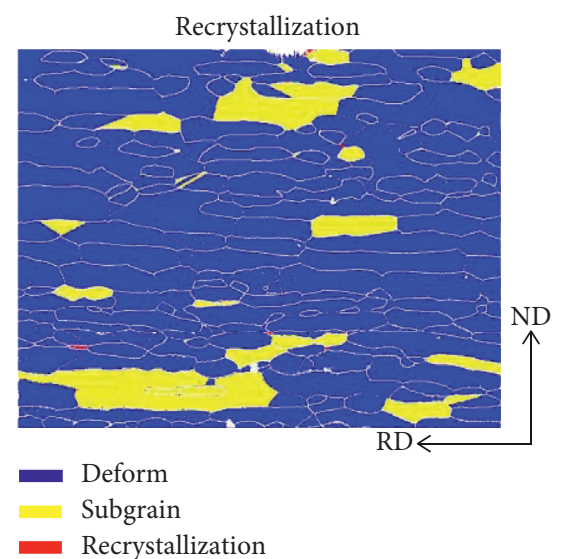

(1)

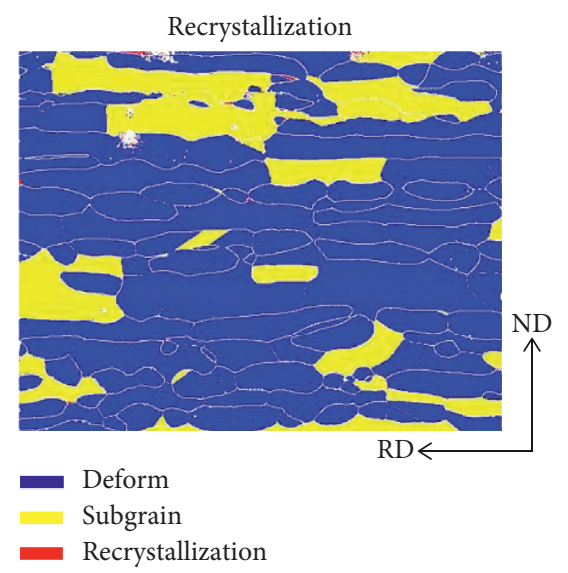

(o)

Figure 1: Microstructure of 2205 duplex stainless steel at different solution temperatures: (a-c) $1000^{\circ} \mathrm{C},(\mathrm{d}-\mathrm{f}) 1040^{\circ} \mathrm{C},(\mathrm{g}-\mathrm{i}) 1080^{\circ} \mathrm{C}$, (j-l) $1120^{\circ} \mathrm{C}$, and $(\mathrm{m}-\mathrm{o}) 1160^{\circ} \mathrm{C}$.

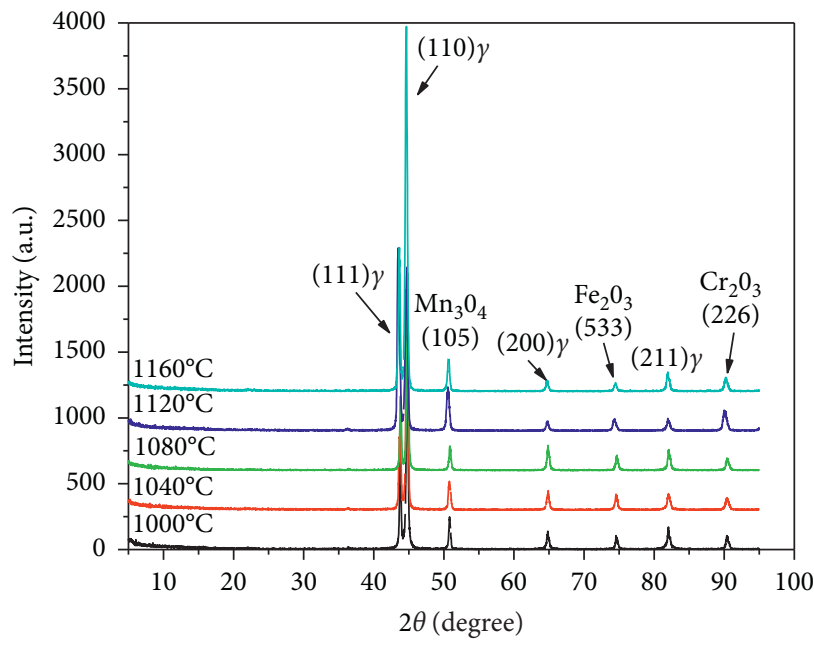

(a)

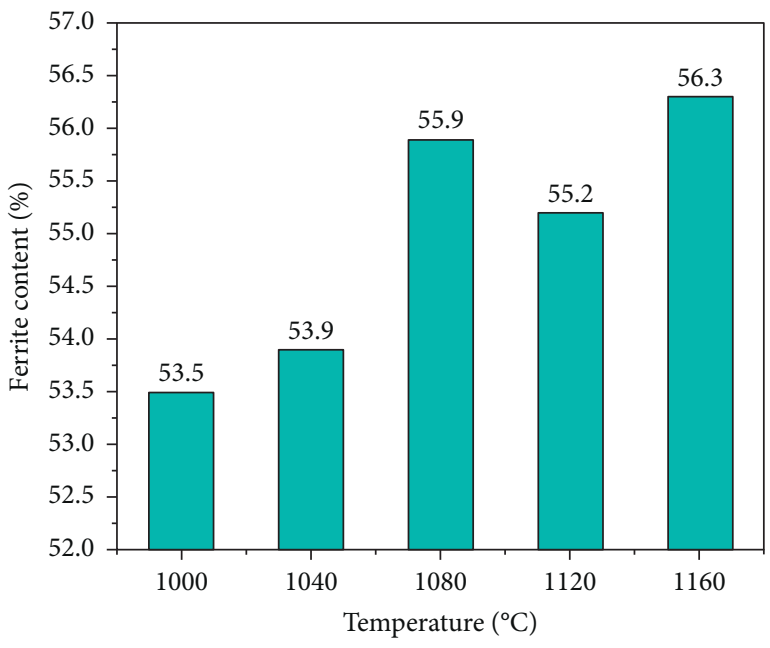

(b)

FIGURE 2: (a) X-ray diffraction patterns of the duplex stainless steel surface. (b) Ferrite phase proportion of 2205 duplex stainless steel at different solution temperatures. 


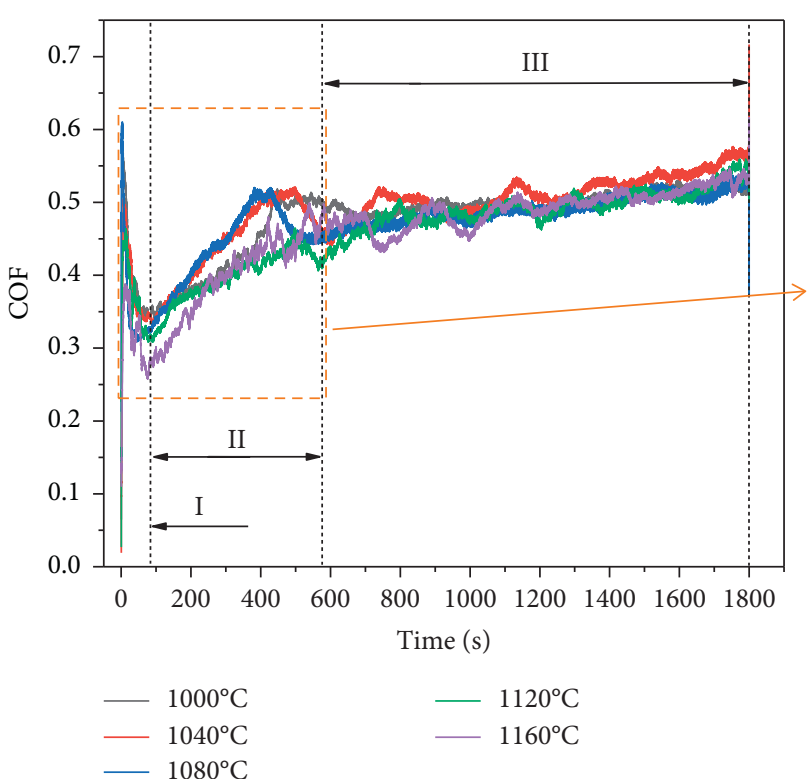

(a)

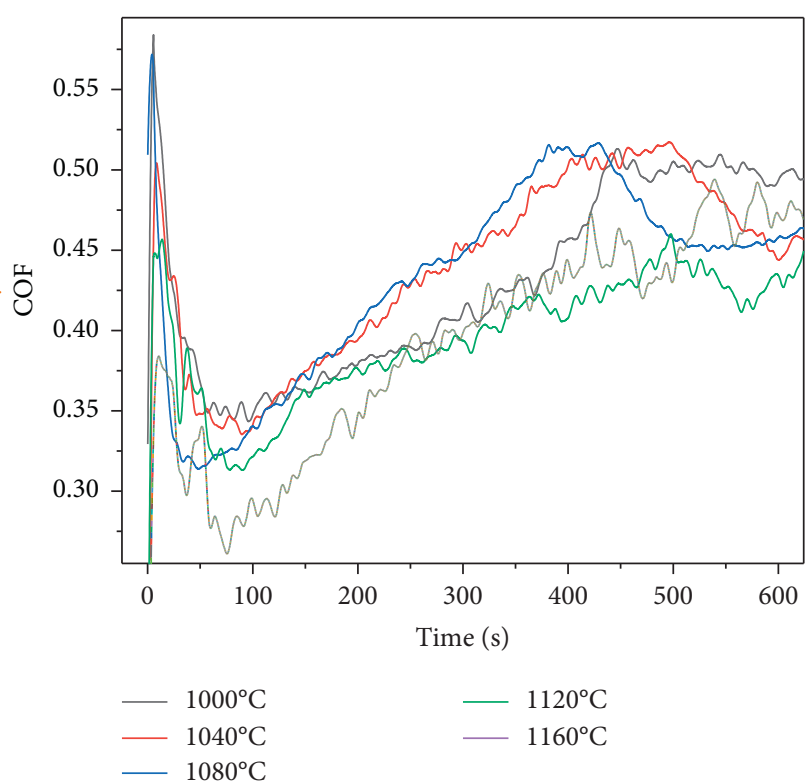

(b)

FIGURE 3: Relationship between friction coefficient and dry friction time at different solution temperatures.

has a certain roughness, so the contact area between the $\mathrm{Si}_{3} \mathrm{~N}_{4}$ ball and the material surface is small. This leads to an increase in contact stress and wear rate. The subsequent decrease in the friction coefficient is due to the rapid wear of the ball and the material surface, which makes the interface smoother and the contact area smaller. Besides, the wear debris between the friction pairs acts like ball bearings to reduce the friction coefficient. In the second stage, as the friction continues to increase, the actual contact area also increases, resulting in a further increase in the friction coefficient. After about $400 \mathrm{~s}$, the wear debris between the friction pairs increases to such a level that the friction coefficient decreases. In the third stage, plastic deformation leads to work hardening with the increase in the degree of wear, but the surface contact area remains almost constant. Therefore, the wear increases slowly with time $[30,31]$, and the friction coefficient increases slowly and stably.

In the first stage, the peak value of the friction coefficient increases along with a rise in solution temperature. This may be due to the increase in the microstructure and wear rate of 2205 dual-phase steel resulting from the solution temperature increase. As Figure 3 shows, the highest value of the coefficient at $1160^{\circ} \mathrm{C}$ is 0.27 . In the second stage, the friction coefficient reaches a peak of 0.52 at $1040^{\circ} \mathrm{C}$ and $1080^{\circ} \mathrm{C}$. The peak value of the friction coefficient at $1120^{\circ} \mathrm{C}$ and $1160^{\circ} \mathrm{C}$ is 0.45 , which is lower than for the other solution temperatures. This is because an increase in the solution temperature results in the alloy elements in 2205 dual-phase steel dissolving in the matrix, thus improving the material strength [32]. Under the same load, the actual contact area and friction coefficient are lower. In the third stage, the friction coefficients for the five solution temperatures are all very similar and increase slowly.
3.3. Effect of Solution Temperature on the Wear Macromorphology. Friction and wear tests were carried out on different 2205 duplex stainless steel samples. The macromorphology and cross-section morphology of the samples after the test are shown in Figure 4. Results of the friction and wear test indicate that the macrostate of wear was similar for all solution temperatures, and the depth and width were about $85-94 \mu \mathrm{m}$ and $1.5 \mathrm{~mm}$, respectively.

Figure 5 shows the wear volume of the 2205 duplex stainless steel under different solution treatment conditions. Combined with the results of the analysis on the microstructure and the friction coefficient, this situation may be due to the solution strengthening effect of the 2205 dualphase steel that occurred with the increase in solution temperature. This causes the wear volume to decrease, and the grain growth makes the strength and wear resistance to decrease.

3.4. Analysis of the Micromorphology of Friction and Wear. Figure 6 shows the wear morphology (from middle to edge) and surface oxygen energy spectrum distribution of dualphase steel at different solution temperatures under dry friction conditions. By comparing this with the results shown in Figure 5, it can be seen that the wear track of the dual-phase steel under different solution temperatures is very similar, indicating that the wear mechanism of the five groups of samples is essentially the same. The reciprocal sliding of the silicon nitride ball causes the deformation of 2205 dual-phase steel and results in cutting or ploughing. Microcracks appear on the surface of the 2205 dual-phase steel under the repeated action of the contact compressive stress of the silicon nitride ball and then peel off. The cracks can be easily seen in Figure 6. At $1000^{\circ} \mathrm{C}$, there is a lot of 

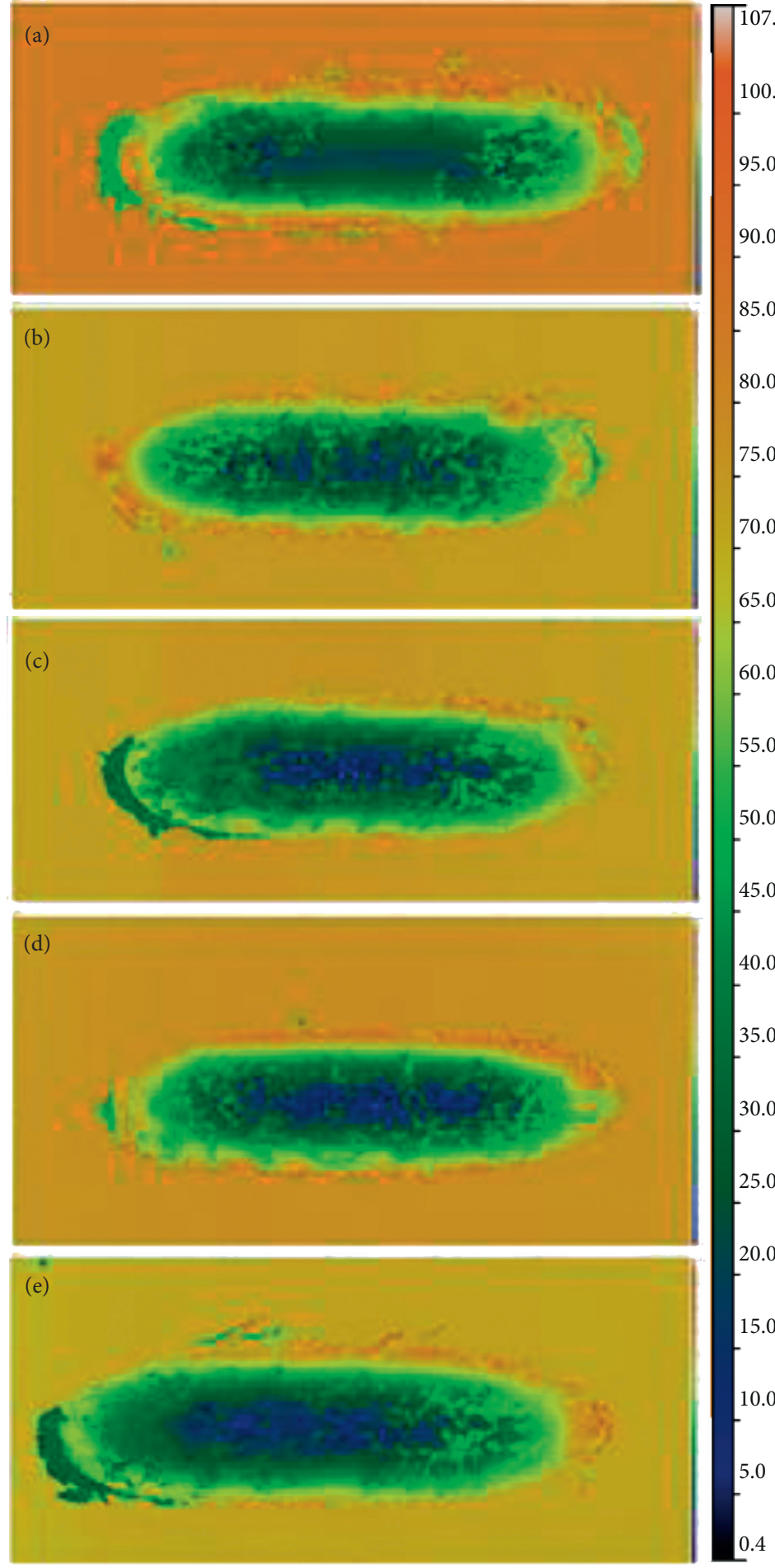
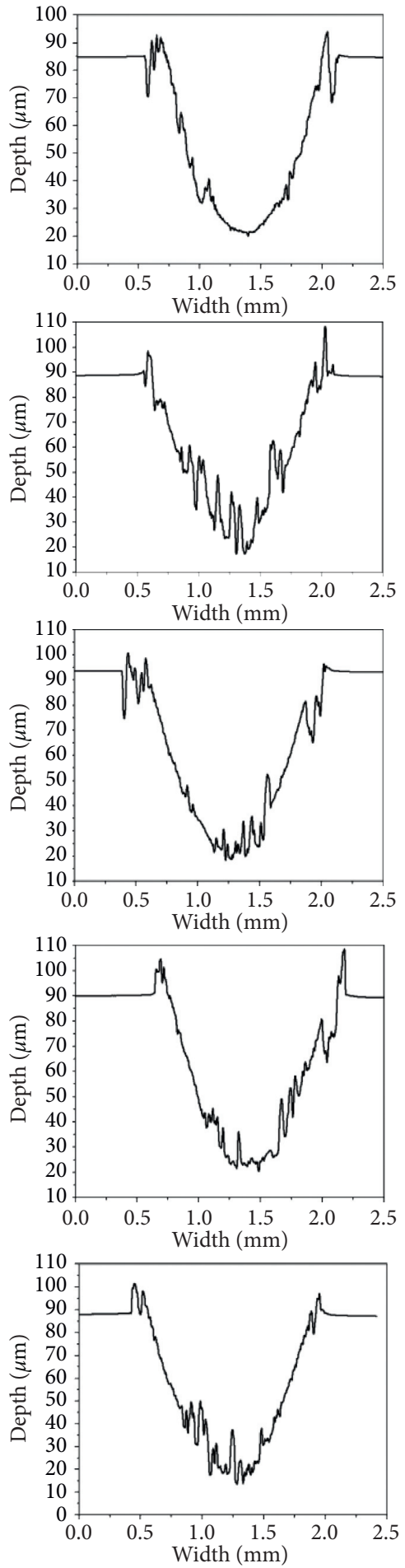

FIGURE 4: Wear macromorphology and cross-section morphology of samples at different solution temperatures: (a) $1000^{\circ} \mathrm{C}$, (b) $1040^{\circ} \mathrm{C}$, (c) $1080^{\circ} \mathrm{C}$, (d) $1120^{\circ} \mathrm{C}$, and (e) $1160^{\circ} \mathrm{C}$.

spalling, and the corresponding oxygen distribution map shows that the oxygen distribution at this temperature is the least. With a rise in solution temperature, the spalling layer presents a similar morphology. When the temperature rises, oxygen in the oxygen element distribution diagram shows a steady increasing trend. When the temperature is $1160^{\circ} \mathrm{C}$, the distribution area of oxygen is the largest. This may be related to an increase in the grain size resulting from the rise in the solution temperature ranged from $1000^{\circ} \mathrm{C}$ to $1160^{\circ} \mathrm{C}$. In the friction and wear process, the compressive stress at the contact point of the asperities on the sample surface can reach more than $4000 \mathrm{MPa}$ and reach high temperatures of more than $1000^{\circ} \mathrm{C}$ instantaneously [33]. Coarse grains are prone to high-temperature oxidation under compressive 


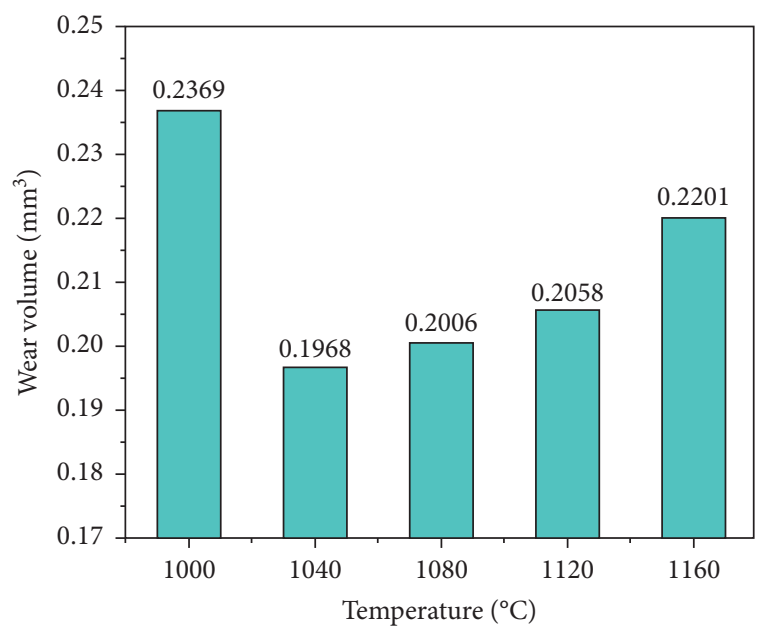

Figure 5: Wear volume of 2205 duplex stainless steel at different solution temperatures.
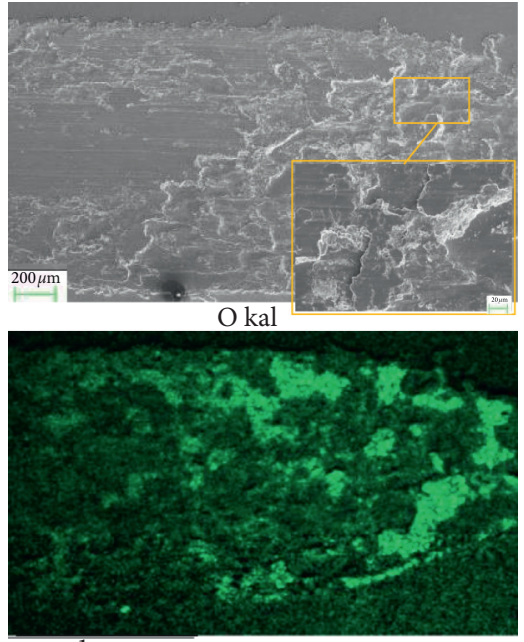

$1 \mathrm{~mm}$

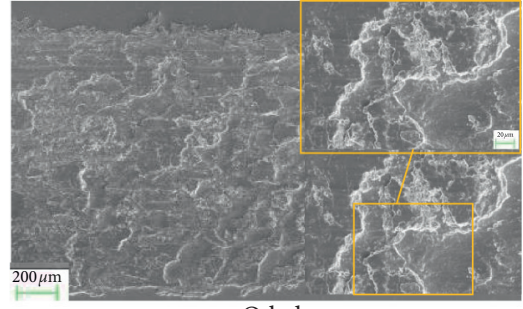

$\mathrm{O} \mathrm{kal}$

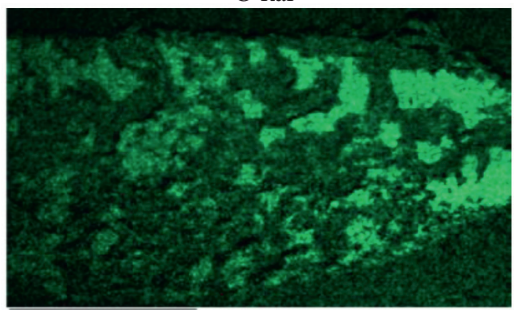

$1 \mathrm{~mm}$

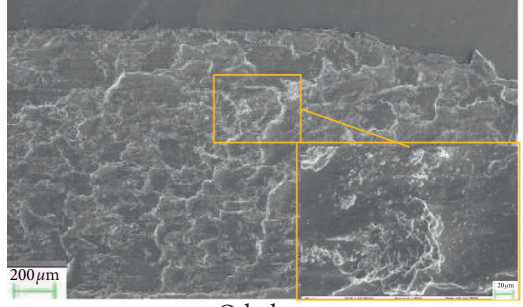

O kal

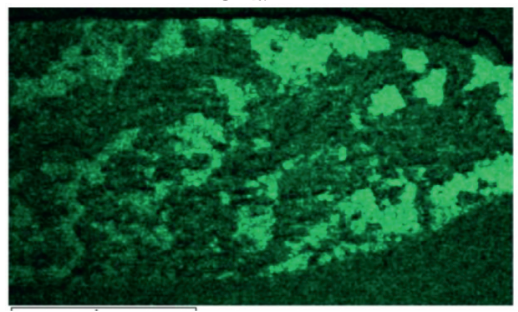

$1 \mathrm{~mm}$

(a)

(b)

(c)
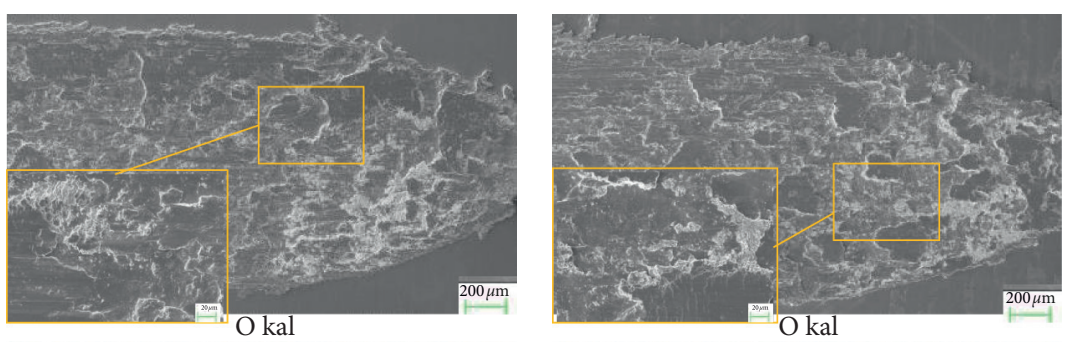

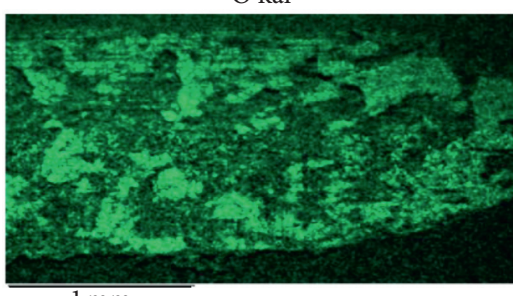

$1 \mathrm{~mm}$

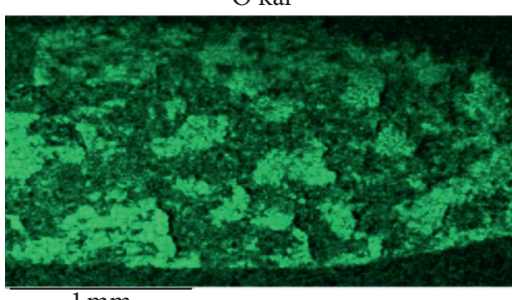

$1 \mathrm{~mm}$

(d)

(e)

FIGURE 6: Wear morphology (from middle to edge) and surface oxygen energy spectrum distribution of dual-phase steel at different solution temperatures under dry friction conditions. 
stress. Therefore, under $100 \mathrm{~N}$ dry friction, with the increase of solution temperature and oxygen distribution area, the wear mechanism of 2205 dual-phase steel gradually expanded from local oxidation wear to adhesive wear and exfoliation wear.

\section{Conclusion}

(1) As the solution temperature rises, the fiber-like austenite phase in 2205 duplex stainless steel gradually evolves into a short rod-like and island-like morphology, and the grain/phase boundaries become clearer. The content of the ferrite phase in the microstructure increases gradually, and the content of the ferrite phase can reach $56.3 \%$ at $1160^{\circ} \mathrm{C}$.

(2) Results show that the friction coefficient curves of 2205 dual-phase steel and silicon nitride balls have similar characteristics between $1000^{\circ} \mathrm{C}$ and $1160^{\circ} \mathrm{C}$. The friction coefficient first increases rapidly, reaches a peak value, and then decreases at a fast rate before gradually and stably increasing. In the first stage, the peak value of the friction coefficient falls with an increase in the solution temperature. In the second stage, the friction coefficient at $1040^{\circ} \mathrm{C}$ and $1080^{\circ} \mathrm{C}$ reaches the peak value of 0.52 , while in this stage, the friction coefficient at $1120^{\circ} \mathrm{C}$ and $1160^{\circ} \mathrm{C}$ only reaches a maximum value of 0.45 . In the third stage, the friction coefficients of the five samples are almost identical, and all increase slowly.

(3) Under $100 \mathrm{~N}$ dry friction, with the increase of solution temperature and oxygen distribution area, the wear mechanism of 2205 dual-phase steel gradually expanded from local oxidation wear to adhesive wear and exfoliation wear.

\section{Data Availability}

All the data that support the findings of this study are included within the article.

\section{Conflicts of Interest}

The authors declare that there are no conflicts of interest.

\section{Acknowledgments}

This project was supported by the National Natural Science Foundation Project of China (Grant no. 52075356), 2019 Key R\&D Project (International Scientific and Technological Cooperation) of Shanxi Province (Grant no. 201903D421005), and Graduate Education Innovation Project of Shanxi Province (Grant no. 2019BY119).

\section{References}

[1] M. B. Mampuya, M. C. Umba, K. Mutombo, and P. A. Olubambi, "Effect of heat treatment on the microstructure of duplex stainless steel 2205," Materials Today: Proceedings, vol. 38, pp. 1107-1112, 2021.
[2] Y. Tang, "Investigation of influence of surface roughness on pitting corrosion of duplex stainless steel 2205 using various electrochemical techniques," International Journal of Electrochemical Science, vol. 14, pp. 6790-6813, 2019.

[3] Z. Tao, C. Zhu, M. He, and M. Karakus, "A physical modelingbased study on the control mechanisms of negative Poisson's ratio anchor cable on the stratified toppling deformation of anti-inclined slopes," International Journal of Rock Mechanics and Mining Sciences, vol. 138, Article ID 104632, 2021.

[4] C. Zhu, M. He, M. Karakus, X. Zhang, and Z. Tao, "Numerical simulations of the failure process of anaclinal slope physical model and control mechanism of negative Poisson's ratio cable," Bulletin of Engineering Geology and the Environment, vol. 80, no. 4, pp. 3365-3380, 2021.

[5] Y. Wang, W. K. Feng, R. L. Hu, and C. H. Li, "Fracture evolution and energy characteristics during marble failure under triaxial fatigue cyclic and confining pressure unloading (FC-CPU) conditions," Rock Mechanics and Rock Engineering, vol. 54, no. 2, pp. 799-818, 2021.

[6] L. Jinlong, H. Jin, and L. Tongxiang, "The effect of electrochemical nitridation on the corrosion resistance of the passive films formed on the 2205 duplex stainless steel," Materials Letters, vol. 256, Article ID 126640, 2019.

[7] X. Yang, J. Wang, C. Zhu, M. He, and Y. Gao, "Effect of wetting and drying cycles on microstructure of rock based on SEM," Environmental Earth Sciences, vol. 78, no. 6, p. 183, 2019.

[8] Y. Song, S. Wang, G. Zhao, Y. Li, L. Juan, and Z. Jian, "Hot deformation behavior and microstructural evolution of 2205 duplex stainless steel," Materials Research Express, vol. 7, no. 4, Article ID 046510, 2020.

[9] K. Vijayalakshmi, V. Muthupandi, and R. Jayachitra, "Influence of heat treatment on the microstructure, ultrasonic attenuation and hardness of SAF 2205 duplex stainless steel," Materials Science and Engineering: A, vol. 529, no. 1, pp. 447-451, 2011.

[10] J. Nachazel, P. Martínek, P. Podany, and I. Polakova, "Effect of heat treatment on the microstructure of duplex stainless steel," Applied Mechanics and Materials, vol. 751, pp. 9-14, 2015.

[11] Q.-X. Meng, W.-Y. Xu, H.-L. Wang, X.-Y. Zhuang, W.-C. Xie, and T. Rabczuk, "DigiSim-an open source software package for heterogeneous material modeling based on digital image processing," Advances in Engineering Software, vol. 148, Article ID 102836, 2020.

[12] C. Zhu, M.-C. He, M. Karakus, X.-H. Zhang, and Z. Guo, “The collision experiment between rolling stones of different shapes and protective cushion in open-pit mines," Journal of Mountain Science, vol. 18, no. 5, pp. 1391-1403, 2021.

[13] Q. Wang, Z. Jiang, B. Jiang, H. Gao, Y. Huang, and P. Zhang, "Research on an automatic roadway formation method in deep mining areas by roof cutting with high-strength boltgrouting," International Journal of Rock Mechanics and Mining Sciences, vol. 128, Article ID 104264, 2020.

[14] J. X. Zhang, W. W. Li, and Q. Y. Li, "State-of-the-art weldability of the 2205 duplex stainless steel," Welded Pipe and Tube, vol. 28, no. 5, pp. 6-10, 2005.

[15] Y. Mao, Y. Zheng, Y. Shi et al., "Effect of rolling deformation on microstructure and mechanical properties of 2205 duplex stainless steel with micro-nano structure," Modern Physics Letters B, vol. 34, no. 25, Article ID 2050269, 2020.

[16] X. J. Meng, F. Y. Meng, W. W. Song et al., "Effect of two kinds of heat treatment on corrosion behavior of 2205 duplex 
stainless steel," Corrosion \& Protection, vol. 33, no. 7, pp. 563-566, 2012.

[17] B. Li, R. Bao, Y. Wang, R. Liu, and C. Zhao, "Permeability evolution of two-dimensional fracture networks during shear under constant normal stiffness boundary conditions," Rock Mechanics and Rock Engineering, vol. 54, no. 1, pp. 409-428, 2021.

[18] J. C. Zheng, Study on the Resistance to Corrosion of Duplex Stainless Steel 2205, pp. 34-45, University of Science and Technology Beijing, Beijing, China, 2019.

[19] Q. Wang, H. Gao, B. Jiang, S. Li, M. He, and Q. Qin, "In-situ test and bolt-grouting design evaluation method of underground engineering based on digital drilling," International Journal of Rock Mechanics and Mining Sciences, vol. 138, Article ID 104575, 2021.

[20] Q. Wang, Q. Qin, B. Jiang et al., "Mechanized construction of fabricated arches for large-diameter tunnels," Automation in Construction, vol. 124, Article ID 103583, 2021.

[21] A. Li, F. Dai, Y. Liu, H. Du, and R. Jiang, "Dynamic stability evaluation of underground cavern sidewalls against flexural toppling considering excavation-induced damage," Tunnelling and Underground Space Technology, vol. 112, Article ID 103903, 2021.

[22] X. Wang, L. Huang, H. Wang, C. Ma, and J. Luo, "Influence of solution treatment on microstructure and properties of duplex stainless steel," Heat Treatment of Metals, vol. 43, no. 5, pp. 101-105, 2018.

[23] R. Djeridi and M. Ould Ouali, "Experimental modeling of wear behavior of filled elastomer SBR under dry frictioninfluence of roughness," Key Engineering Materials, vol. 640, pp. 13-20, 2015.

[24] V. Abouei, H. Saghafian, S. Kheirandish et al., "A study on the wear behaviour of dual phase steels," Materials Science and Technology, vol. 023, no. 1, pp. 107-110, 2007.

[25] A. Bayram and A. Uğuz, "Effect of microstructure on the wear behaviour of a dual phase steel," Materialwissenschaft und Werkstoffechnik, vol. 32, no. 3, pp. 249-252, 2001.

[26] M. J. Wang, Y. X. Wang, N. Fan, Q. F. Wang, and F. Y. Yan, "Fretting wear properties of 2507 super duplex stainless steel in artificial seawater," Lubrication Engineering, vol. 44, no. 2, pp. 24-30, 2019.

[27] Y. T. Wang, P. L. Mao, L. J. Chen, Y. B. Ren, B. C. Zhang, and K. Yang, "Fabrication technology of high nitrogen austenite layer on surface of duplex stainless steel," Journal of Shenyang University of Technology, vol. 3, pp. 49-52, 2007.

[28] Q. Bai and Z. Zhang, "Effect of solution treatment temperature on phase ration and mechanical properties of 2507 super duplex stainless steel," Heat Treatment of Metals, vol. 9, pp. 123-126, 2019.

[29] Y. Xue, S. Yan, J. Xie, Z. Feng, and J. Zou, "Contact and tribological properties of self-lubricating ellipsoidal plain bearings," Tribology International, vol. 140, Article ID 105840, 2019.

[30] L. Shan, Y. Wang, J. Li, X. Jiang, and J. Chen, "Improving tribological performance of CrN coatings in seawater by structure design," Tribology International, vol. 82, pp. 78-88, 2015.

[31] R. Yang, W. Ma, C. J. Duan et al., "Microstructure responses and deformation mechanisms of solutionized Ti-51.5 at.\% Ni alloy during reciprocating sliding," Tribology International, vol. 140, Article ID 105816, 2019.

[32] F. Xie, J. W. Pan, and H. Yuan, "Optimizing heat treatment for a duplex stainless steel," Transactions of Materials and Heat Treatment, vol. 31, no. 9, pp. 68-72, 2010.
[33] S. Z. Wen and P. Huang, Principles of Tribologypp. 62-78, Tsinghua University Press, Beijing, China, 3rd edition, 2008. 